\title{
The Filum disease and the Neuro-Cranio- vertebral syndrome: definition, clinical picture and imaging features
}

\author{
Miguel B. Royo-Salvador ${ }^{1 *}$, Marco V. Fiallos-Rivera', Horia C. Salca ${ }^{1}$ and Gabriel Ollé-Fortuny ${ }^{2}$
}

\begin{abstract}
Background: We propose two new concepts, the Filum Disease (FD) and the Neuro-cranio-vertebral syndrome (NCVS), that group together conditions thus far considered idiopathic, such as Arnold-Chiari Syndrome Type I (ACSI), Idiopathic Syringomyelia (ISM), Idiopathic Scoliosis (IS), Basilar Impression (BI), Platybasia (PTB) Retroflexed Odontoid $(\mathrm{RO})$ and Brainstem Kinking (BSK).

Method: We describe the symptomatology, the clinical course and the neurological signs of the new nosological entities as well as the changes visible on imaging studies in a series of 373 patients.

Results: Our series included $72 \%$ women with a mean age of 33.66 years; $48 \%$ of the patients had an interval from onset to diagnosis longer than 10 years and $64 \%$ had a progressive clinical course. The commonest symptoms were: headache $84 \%$, lumbosacral pain $72 \%$, cervical pain $72 \%$, balance alteration $72 \%$ and paresthesias $70 \%$. The commonest neurological signs were: altered deep tendon reflexes in upper extremities $86 \%$, altered deep tendon reflexes in lower extremities $82 \%$, altered plantar reflexes $73 \%$, decreased grip strength $70 \%$, altered sensibility to temperature 69\%, altered abdominal reflexes 68\%, positive Mingazzini's test 66\%, altered sensibility to touch 65\% and deviation of the uvula and/or tongue 64\%. The imaging features most often seen were: altered position of cerebellar tonsils 93\%, low-lying Conus medullaris below the T12L1 disc 88\%, idiopathic scoliosis 76\%, multiple disc disease 72\% and syringomyelic cavities 52\%.
\end{abstract}

Conclusions: This is a paradigm shift that opens up new paths for research and broadens the range of therapeutics available to these patients.

Keywords: Arnold-Chiari syndrome, Syringomyelia, Scoliosis, Filum terminale

\section{Background}

This paper summarizes and culminates the endeavors of various researchers who have been pursuing so far three convergent lines of research: the tethered cord syndrome; the etiopathogenic relationship between ArnoldChiari Syndrome Type I, Idiopathic Syringomyelia and Idiopathic Scoliosis and other associated pathologies;

\footnotetext{
* Correspondence: mroyo@institutchiaribcn.com

${ }^{1}$ Institut Chiari \& Siringomielia \& Escoliosis de Barcelona, Passeig Manuel Girona 16, 08034 Barcelona, Spain

Full list of author information is available at the end of the article
}

and finally, the role of spinal cord tethering in the development of Idiopathic Scoliosis.

Even though the first surgical cases of tethered cord release were published already as early as 1857 by Johnson [1] and in 1891 by Jones WL [2], the relationship between tethering of the spinal cord and a certain neurological and spinal symptomatology, i.e. the first concept of tethered cord, was suggested by Fuchs [3] in 1909 in patients with myelomeningocele, as did Lichtenstein [4] later in 1940.

(C) The Author(s). 2020 Open Access This article is licensed under a Creative Commons Attribution 4.0 International License, which permits use, sharing, adaptation, distribution and reproduction in any medium or format, as long as you give appropriate credit to the original author(s) and the source, provide a link to the Creative Commons licence, and indicate if changes were made. The images or other third party material in this article are included in the article's Creative Commons licence, unless indicated otherwise in a credit line to the material. If material is not included in the article's Creative Commons licence and your intended use is not permitted by statutory regulation or exceeds the permitted use, you will need to obtain permission directly from the copyright holder. To view a copy of this licence, visit http://creativecommons.org/licenses/by/4.0/ The Creative Commons Public Domain Dedication waiver (http://creativecommons.org/publicdomain/zero/1.0/) applies to the data made available in this article, unless otherwise stated in a credit line to the data. 
In 1953, Garceau [5] defined the "filum terminale syndrome", or "cord-traction syndrome", reporting on three cases with a similar picture, that improved after sectioning of a thick and tight filum terminale, whereas Jones and Love [6] proposed in 1956 the term "tight filum terminale".

In 1976, Hoffmann [7] was using the term "tethered spinal cord" to define a similar clinical picture, associated to certain radiological criteria such as a low-lying medullary conus and a thick filum terminale.

As a result of these consecutive contributions, after many decades of indecision and difficulties, the tethered cord syndrome was finally described, as caused by an abnormal tethering of the spinal cord by a malformation that is evident on physical examination in the form of a spina bifida, while manifesting by a clinical picture of neurological sensorimotor impairments, predominantly in the lower limbs, associated with frequent deformities of the feet, cutaneous stigmata and genitourinary alterations, according to Fuchs, Lichtenstein and Yamada [3, $4,8]$. The prevalence of a symptomatic tethered cord associated with spina bifida occulta was $0.1 \%$ of 5499 primary school children in Turkey [9], while generally, all types of spina bifida occur in the range of $0.5-10$ per 1000 live births worldwide [10]. The surgical treatment, indicated in $10-20 \%$ of cases, consists in the release of the spinal cord that is tethered by the myelo-meningovertebral malformation, via a lumbar laminectomy.

On the other hand, in a quite distinct direction of research, many authors observed an association amongst Arnold-Chiari Syndrome Type I, Idiopathic Syringomyelia and Idiopathic Scoliosis over the past decades [11-18] but no pathogenic explanation or possible causal relationship has been sufficiently accepted in order to warrant the initiation of more in-depth studies into this matter.

Finally, a third line of research, very close to our own vision, attempts to explain the pathogenesis of Idiopathic Scoliosis, Arnold-Chiari Syndrome Type I and Basilar Impression with a growth asynchrony between the spine and the spinal cord - a mechanism proposed by Roth in 1981 and 1986 [19, 20]. This would be causing a tethering of the spinal cord, as Porter advanced in 2001 [21, 22 ], and an excessive and deforming growth of the anterior elements of the thoracic spine, leading to the production of scoliosis with rotation, according to a mechanism suggested by Dickson in 1984 [23]. Some recent magnetic resonance studies, particularly those carried out by Winnie Chou's team, have identified features which support these theories in IS patients [24], while others, as Milhorat in 2009, have applied these criteria for treatment [25].

Based on the arguments outlined in the doctoral thesis "Contribution to the etiology of syringomyelia" [26], the traction of the spinal cord and brain is proposed as the main mechanism involved in the etiopathogenesis of ISM, ACSI, IS and other diseases also considered idiopathic, such as Platybasia, Basilar Impression, Retroflexed Odontoid and Brainstem Kinking [27, 28].

The objective of this article is to introduce the concept Neuro-Cranio-Vertebral Syndrome (NCVS) to define the set of clinical and imaging manifestations that affect the nervous system, the skull and the spine in the form of known diseases like Arnold-Chiari Syndrome Type I, Idiopathic Syringomyelia, Idiopathic Scoliosis and other anomalies like Platybasia, Basilar Impression, Retroflexed Odontoid and Brainstem Kinking. The Filum Disease is the most frequent congenital form of the Neuro-CranioVertebral Syndrome.

\section{Methods}

Between the 14th of April, 2009 and 16th of December, 2015, 1285 patients with one or several of the diagnoses of Arnold-Chiari Syndrome Type I, Idiopathic Syringomyelia, Idiopathic Scoliosis, Platybasia, Basilar Impression, Brainstem Kinking, low-lying conus medullaris and related pathologies were seen at the Institut Chiari \& Siringomielia $\mathcal{E}$ Escoliosis de Barcelona out of whom, we present the clinical and imaging features in a sample of 373 patients, selected because they presented complete data registered for the purposes of this investigation, after excluding cases with significant neurological or neurosurgical antecedents that could interfere with their clinical or imaging presentation: procedures such as suboccipital craniectomy, syringostomy, ventriculo-peritoneal shunting, instrumentation for scoliosis, discectomies, laminectomies for spinal stenosis, as well as demyelinating, inflammatory, tumorous or traumatic diseases of the central and peripheral nervous system.

Patients generally contact us after having been diagnosed with one or more of these conditions in their home country, because of their interest in our method used for the diagnosis, treatment and follow-up of the Filum Disease and Neuro-Cranio-Vertebral Syndrome, called Filum System $^{\bullet}\left(\mathrm{FS}^{\bullet}\right.$, presented on https://filumsystem.com/enfermedad-del-filum, https://filumsystem.com/enfermedadesimplicadas/ and https://institutchiaribcn.com) as we are the only center qualified to apply it worldwide, as a highly specialized private center holding the Research \& Development (R\&D) certification 1583.001.16-160,920-CERRD.001 from the Spanish Innovation Certification Agency (ACIE) and ENAC certification 33/C-PR074, Certificate IQNet and AENOR Quality Management System ISO 9001:2015, Registration Number: ES-0081/2015 for the following fields of activities: Research, Diagnosis and Treatment of the Filum Disease and Quality Management Certification according to UNE-EN ISO 9001:2008 standards. 
Once the patients have arrived and have been registered at our center, after recording personal and family antecedents, the history focuses on a meticulous interview about possible Neuro-Cranio-Vertebral Syndrome symptoms, according to an anatomical order, followed by an exhaustive and detailed neurological examination centered on the Neuro-Cranio-Vertebral Syndrome and consisting mainly of the procedures presented in Table 1. The majority of patients send magnetic resonance imaging (MRI) series of the whole spine previous to their appointment, including at least sagittal and axial cuts, $\mathrm{T} 1$ as well as T2-weighted, as well as antero-posterior and lateral $x$-ray images of the entire spine taken in standing position. All these are scrutinized in the search for the following pathologies:

Table 1 Neurological examination. ' Currently, we also employ the Jamar dynamometer. ${ }^{2}$ Not included in the statistical analysis

\begin{tabular}{|c|c|c|}
\hline \multicolumn{2}{|c|}{ Procedures } & \multirow{2}{*}{$\begin{array}{l}\text { Findings } \\
\text { Miosis, mydriasis, anisocoria, } \\
\text { diminished reflex to light }\end{array}$} \\
\hline 1. & Pupillary examination & \\
\hline 2. & Oculomotricity & Strabismus, nystagmus \\
\hline 3. & Inspection uvula and tongue & Deviation, asymmetry \\
\hline 4. & $\begin{array}{l}\text { Grip strength measurement } \\
\text { with Collins dynamometer }{ }^{1}\end{array}$ & $\begin{array}{l}\text { Unilateral or bilateral decrease } \\
\text { below the 10th centile of the } \\
\text { corresponding age and gender } \\
\text { group }\end{array}$ \\
\hline 5. & $\begin{array}{l}\text { Deep tendon reflexes, } \\
\text { abdominal reflexes and plantar } \\
\text { reflexes }\end{array}$ & $\begin{array}{l}\text { absent, decreased, brisk, } \\
\text { appearance of pathological } \\
\text { reflexes }\end{array}$ \\
\hline 6. & $\begin{array}{l}\text { Sensibility to temperature in at } \\
\text { least } 40 \text { body areas }\end{array}$ & $\begin{array}{l}\text { Anesthesia, hypoesthesia, } \\
\text { hyperesthesia, dysesthesias or } \\
\text { evoked paresthesias }\end{array}$ \\
\hline 7. & $\begin{array}{l}\text { Sensibility to touch in at least } \\
40 \text { body areas }\end{array}$ & $\begin{array}{l}\text { Anesthesia, hypoesthesia, } \\
\text { hyperesthesia, dysesthesias or } \\
\text { evoked paresthesias }\end{array}$ \\
\hline 8. & Lasègue's test & $\begin{array}{l}\text { Positive if pain elicited, specifying } \\
\text { its location and leg elevation angle }\end{array}$ \\
\hline 9. & Mingazzini's test & Paresis \\
\hline 10. & Reversed Lasègue's test ${ }^{2}$ & $\begin{array}{l}\text { Positive if thigh pain elicited with } \\
\text { flexion of the leg in prone position }\end{array}$ \\
\hline 11. & Barré's test ${ }^{2}$ & Paresis \\
\hline 12. & $\begin{array}{l}\text { Tender points on the back and } \\
\text { lower limbs }{ }^{2}\end{array}$ & $\begin{array}{l}\text { Positive if pain elicited in certain } \\
\text { spots with thumb pressure }\end{array}$ \\
\hline 13. & $\begin{array}{l}\text { Inspection and palpation of } \\
\text { sacral area }\end{array}$ & $\begin{array}{l}\text { Deformation, sacral dimple, } \\
\text { hypersensitivity }\end{array}$ \\
\hline 14. & $\begin{array}{l}\text { Inspection of back, shoulders } \\
\text { and scapulae }\end{array}$ & $\begin{array}{l}\text { Shoulder asymmetry, winged } \\
\text { scapulae waist fold sign thorax, } \\
\text { scoliotic attitude }\end{array}$ \\
\hline 15. & Romberg's test & $\begin{array}{l}\text { Instability, retropulsion or } \\
\text { lateropulsion }\end{array}$ \\
\hline 16. & Toe and heel walking ${ }^{2}$ & Paresis, instability, ataxia \\
\hline 17. & Quadriceps paresis test ${ }^{2}$ & $\begin{array}{l}\text { Positive if difficult or impossible to } \\
\text { stand up from alternate unilateral } \\
\text { kneeling position }\end{array}$ \\
\hline
\end{tabular}

1. Occipitocervical Junction Malformations, of which the most common are: Basilar Impression with the odontoid ascending more than $5 \mathrm{~mm}$ over Chamberlain's line; Platybasia with an increased Boogaard's angle of more than $135^{\circ}$ or a Welcher's basal angle of more than $140^{\circ}$; Retroflexed Odontoid with an inclination of the dens more than $2 \mathrm{~mm}$ behind the prolongation of the basilar line of Thiébaut-Wackenheim-Vrousos; Brainstem Kinking as seen in significant cases of Platybasia (Fig. 1).

Descent of Cerebellar Tonsils (DCT), defined as any descent of one or both cerebellar tonsils underneath the foramen magnum plane, represented by McRae's line. Furthermore, instead of measuring the length of the displacement in millimeters as is customary, we report it in relation to the occipitocervical bony structures reached by the tip of the lowermost tonsil, like the foramen magnum, the posterior arch of the atlas $(\mathrm{C} 1)$ and the spinous process of the axis (C2) (Fig. 2). We also define as Impaction of Cerebellar Tonsils their contact or intimate closeness with McRae's line, that we consider to be an incipient form of Descent of the Cerebellar Tonsils, representing the equivalent of what other authors have denominated "Chiari malformation type 0 ".

2. Intramedullary Cyst (IMC), defined as an idiopathic syringomyelic cavity of any size, shape and location, always having ruled out a tumoral, vascular or inflammatory etiology by the absence of abnormal contrast enhancement, as well as a traumatic etiology by patient's history and absence of any associated traumatic injuries on imaging. Moreover, cavities were classified according to the longitudinal extension along one or more vertebral levels (Fig. 3). We also take into consideration the following two types of presyringomyelic lesions: a) Spinal Cord Ischemia-Edema, defined by an aspect of one or two parallel hyperintense lines within the spinal cord on T2-weighted sagittal images, usually associated with visible medullary edema (as focal hyperintensity) on T2-weighted axial images (Fig. 4) [29] and b) Central Canal Dilatation, when this one becomes visible, but without reaching the diameter of a filiform syringomyelic cavity (Fig. 5).

3. Deviation of the Vertebral Column (DVC) or Idiopathic Scoliosis defined as any coronal plane disalignment resulting in scoliotic curvatures and being detectable on the standing spine $\mathrm{x}$-ray, that we classify into the following three categories: mild, if it is up to $10^{\circ}$ calculated with the Cobb method; moderate, if it measures between 10 and $40^{\circ} \mathrm{Cobb}$ and severe if it is greater than $40^{\circ} \mathrm{Cobb}$ (Fig. 6). We consider the presence of any abnormality of sagittal 


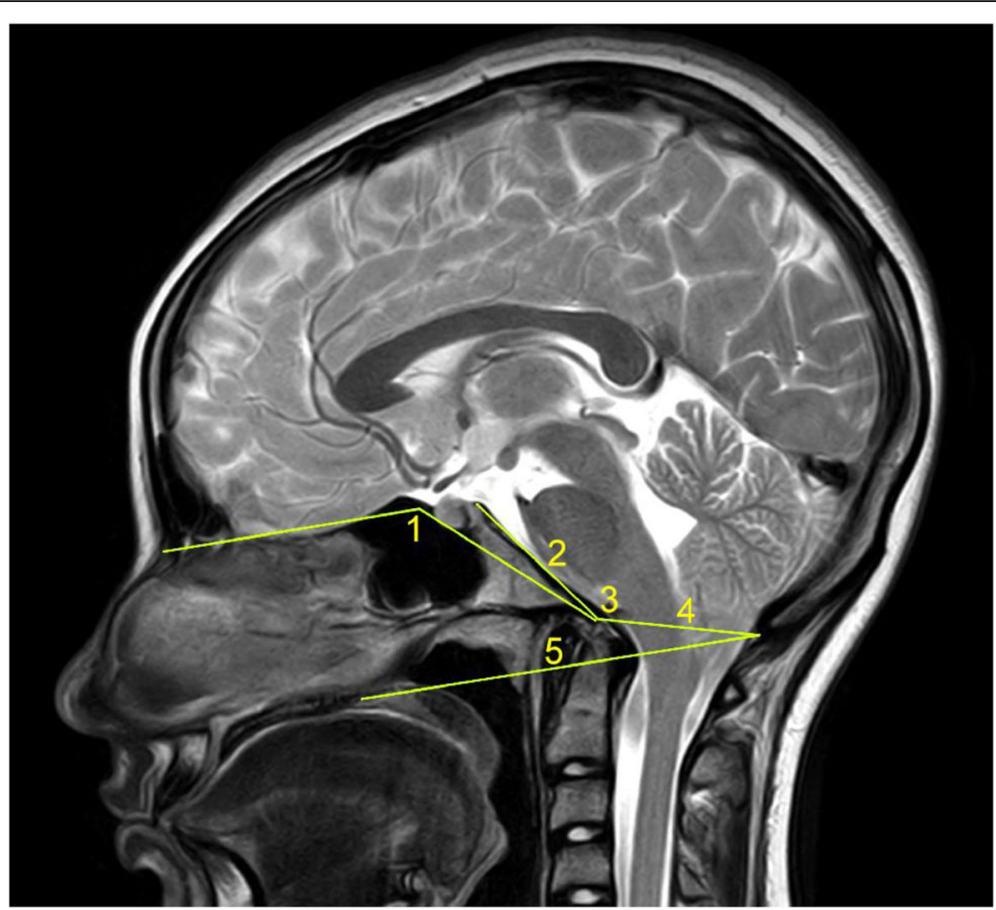

Fig. 1 Parameters employed in the assessment of Occipitocervical Junction Malformations: 1 - Welcher's basal angle; 2 - Thiébaut-WackenheimVrousos' basilar line; 3 - Boogaard's angle; 4 - McRae's line; 5 - Chamberlain's line

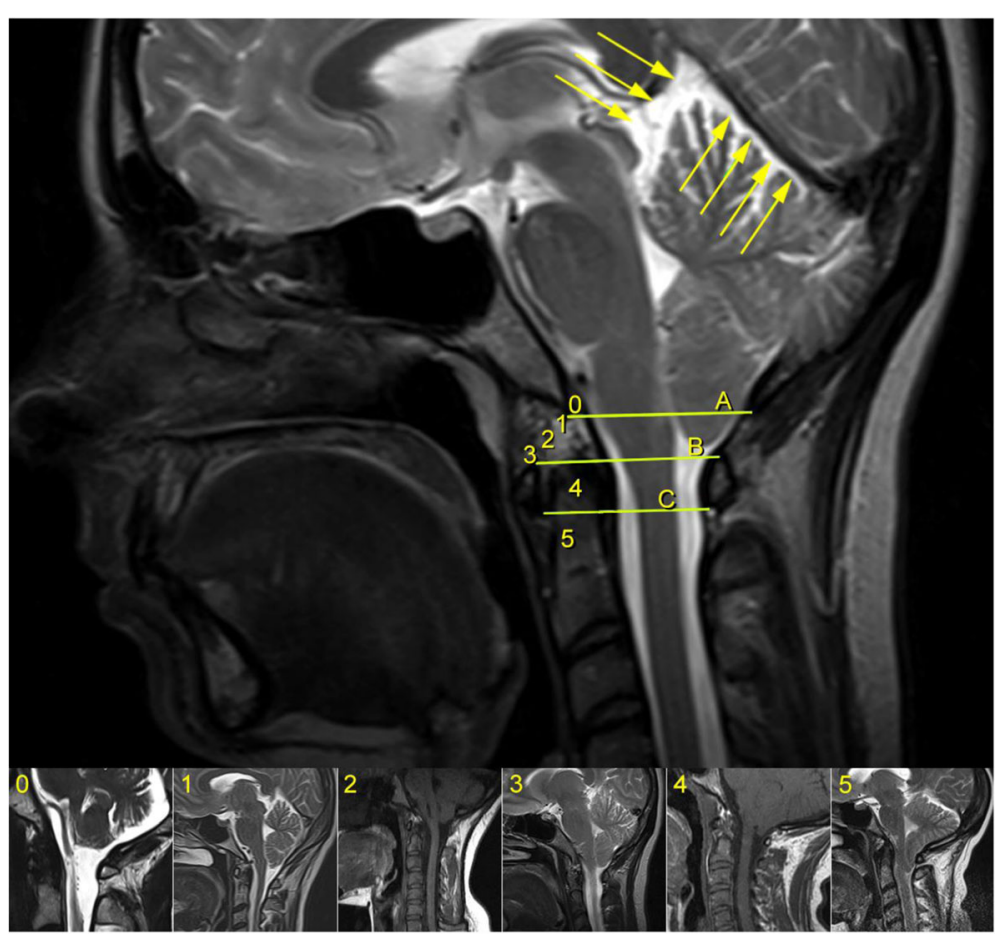

Fig. 2 Classification of the magnitude of DCT with examples for each degree. A - McRae's line (FM); B - Upper border of atlas (C1); C - Lower border of atlas (C1). The interval A-B has been divided into an upper (grade 1), middle (grade 2) and lower (grade 3) third. They are followed by grade 4 - between the upper and lower borders of $\mathrm{C} 1$, and finally grade 5 - Underneath the lower border of $\mathrm{C}$. When the tonsil reaches exactly line $\mathrm{A}$, it is considered grade 0 , that we call Impaction of Cerebellar Tonsils. The arrows indicate another relevant parameter often associated to DCT, the Increase of the Supracerebellar Space 


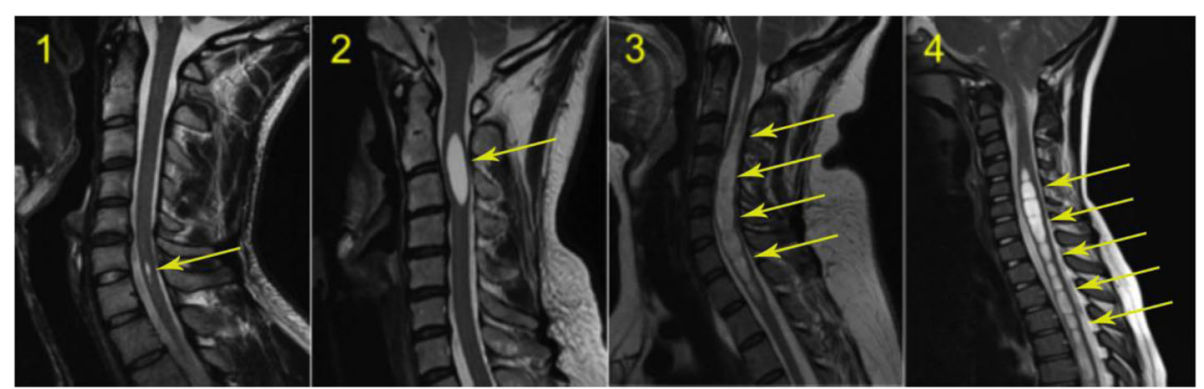

Fig. 3 Classification of the extension of syringomyelic cavities Grade 1 - less than one vertebral segment; grade 2 - between 1 and 5 vertebral segments; grade 3 - between 6 and 10 vertebral segments; grade 4 - more than 10 vertebral segments

spinal curves equally significant as the coronal curve, as proof of an abnormal cord tension, from straightening to inversion of the "physiological" sagittal curvature of any vertebral region.

4. Low-lying Conus Medullaris (LCM), defined as a position of the tip of the medullary conus lower than the D12L1 intervertebral disc, classified according to the corresponding vertebral segment where it reaches, each vertebral body being divided in thirds (Fig. 7).

We often observe as well other suggestive MRI features, for instance the Increase of the Supracerebellar Space (Fig. 2), the Tense Spinal Cord (in sagittal cuts, Figs. 5 and 8) and Lateralized Spinal Cord (in coronal or axial cuts, Fig. 8), a visible Filum terminale internum and/or externum and finally, rotoscoliosis; however, despite being frequent, these changes have not been subject of the statistical analysis in this patient group.

Digital images that came in JPEG format were visualized with the program Preview version 8.1 (Apple, Inc. Cupertino, CA, USA), whilst the majority of them, in DICOM format, were viewed with the program OsiriX version 5.8.2 (Pixmeo SARL, Bernex, Switzerland).
For data analysis, general data, clinical symptoms, clinical signs and imaging features were recorded during the visit of every patient in a table included in a digital database (FileMaker Pro Advanced 11.0v2, FileMaker, Inc. Santa Clara, CA, USA), from where they were transferred to a Microsoft Excel 2011 spreadsheet for Mac version 14.1.0 (Microsoft Corporation, Redmond, WA, USA) and then into an SPPS database (version 21, IBM Corporation, Armonk, NY, USA).

We performed an initial descriptive analysis of the general data (gender, age, type and duration of clinical course), dividing the variables into three main categories: clinical symptoms, clinical signs and imaging features. The variables followed in this study were analyzed looking for associations between components of the three categories mentioned above, taking into account topographical criteria. We used Pearson's chi-squared test and Kendall's test for ordinal data and Mantel-Haenszel chi-square test for stratified data, considering $p<0.05$ as significance threshold. Finally, we created continuous variables by grouping symptoms and signs according to topographical criteria (Table 2) and these variables, as well as the different kinds of imaging features were analyzed together, first through comparison of the means

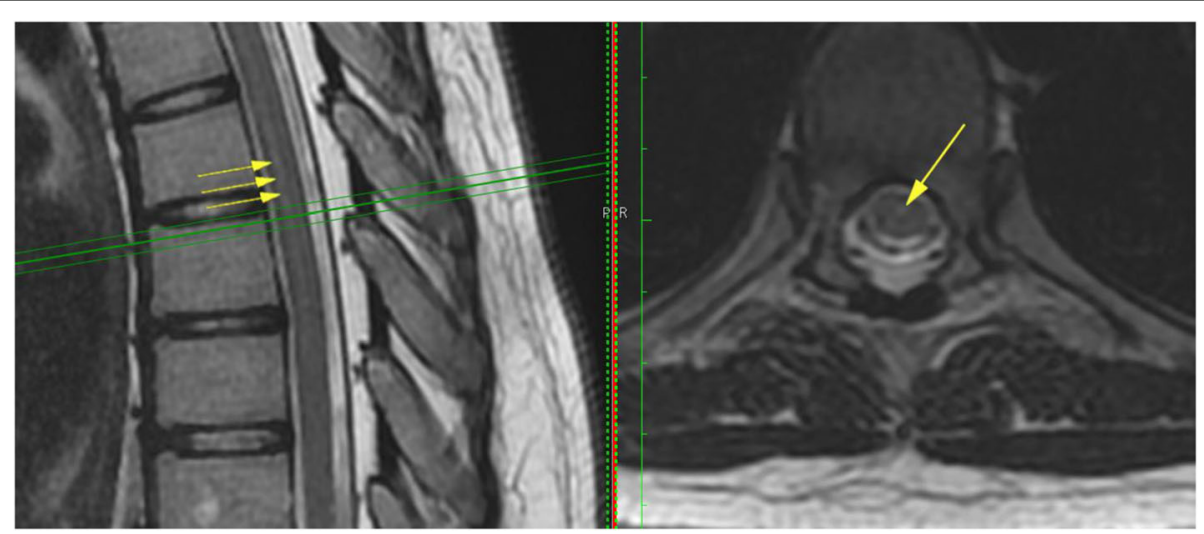

Fig. 4 Spinal Cord Ischemia-Edema visible in a portion of the thoracic spinal cord on the sagittal cut (left, arrows), corresponding with an image of centro-medullary edema on the axial cut (right, arrow) 


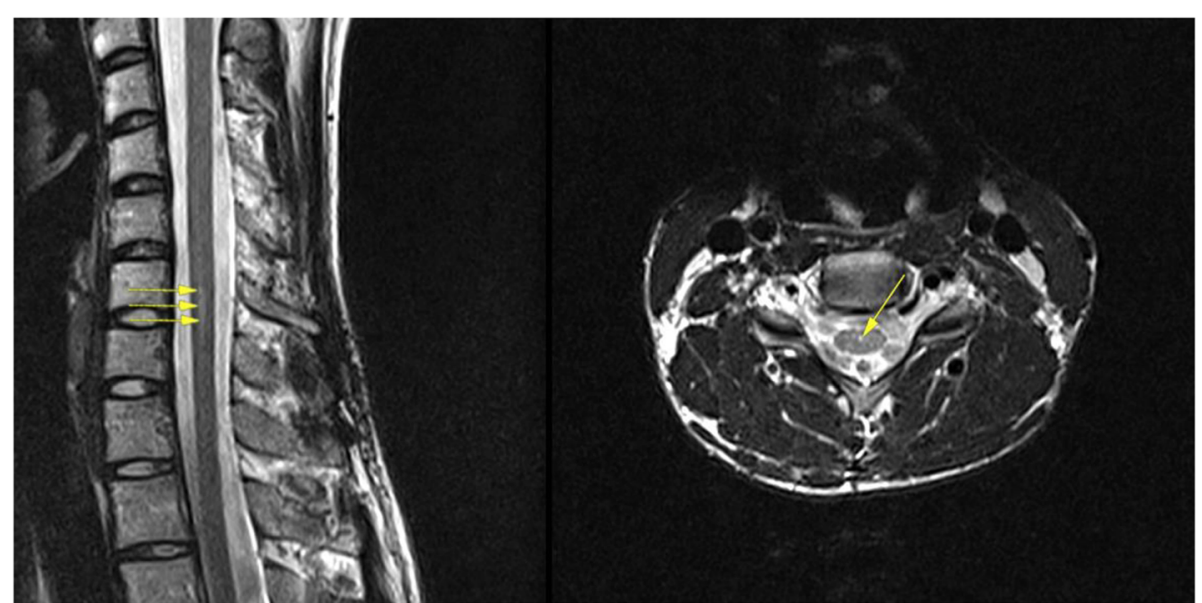

Fig. 5 Central canal dilatation (arrows). There is also a nicely outlined Tense Spinal Cord on the sagittal cut (left)

and Student's $t$-test for independent samples and then through the creation of dispersion diagrams and computing Pearson's correlation coefficient.

\section{Results}

\section{Part I - descriptive analysis}

\section{General data}

Among the 373 selected patients, 270 were females (72\%), with ages between 3 and 76 years (median 33, mean 33.66, standard deviation 15.87). The time interval from the appearance of the first symptoms until the establishment of the diagnosis was greater than 10 years in 177 cases (48\%), between 5 and 10 years in 70 cases (19\%), between 2 and 5 years in 76 cases (20\%) and rarely shorter (Fig. 9).

\section{Neurological clinical picture}

The symptoms detected in more than $10 \%$ of analyzed patients and the clinical signs detected through the specific neurological examination are presented in Tables 3 and 4 .

It is worthwhile to mention that there were other symptoms as well, that we observed quite frequently throughout the study, but as they had not been contemplated in the initial list, they were not assessed in the present analysis and we can only give an overall count of the presence of each one in this patient sample: photophobia in 137 cases (37\%), sonophobia in 126 cases (34\%), involuntary movements or fasciculations in various body parts in 57 cases (15\%) and sensations of electrical current in different regions in 40 cases (11\%).

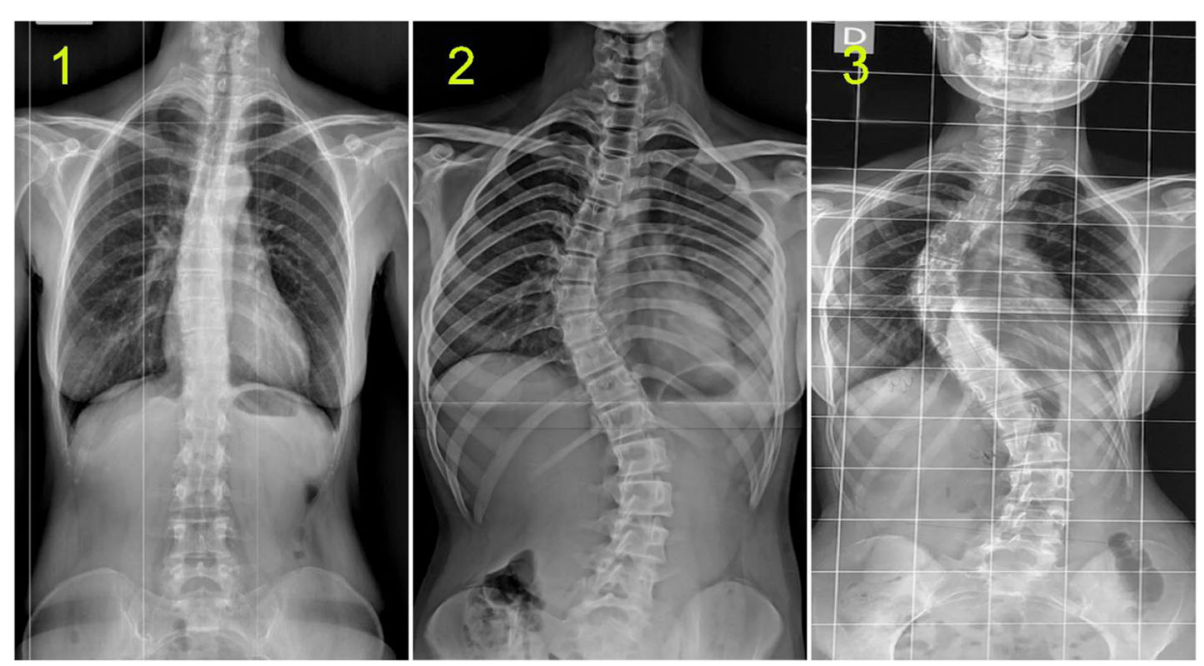

Fig. 6 Classification of Idiopathic Scoliosis. 1 - mild; 2 - modrate; 3 - severe 


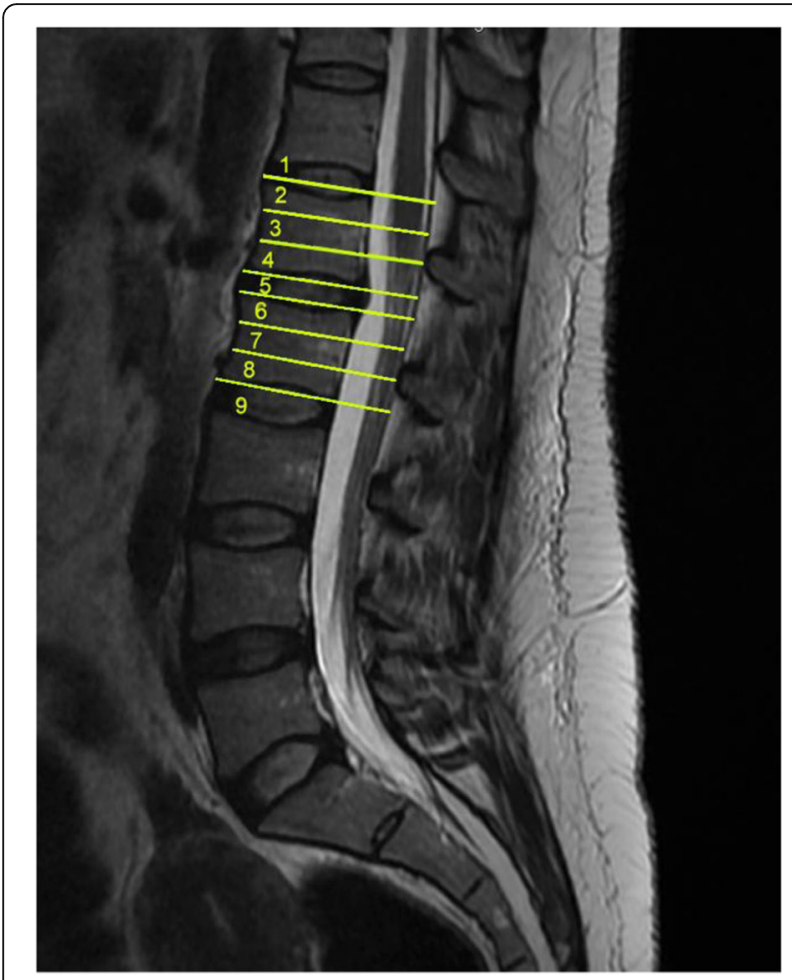

Fig. 7 Levels used in the classification of the depth of the conus medullaris position with regard to vertebral segments: 1 - up to the D12L1 intervertebral disc; 2 - upper third of L1 vertebral body; 3 middle third of $\mathrm{L} 1$ body; 4 - lower third of $\mathrm{L} 1$ body; 5 - L1L2 intervertebral disc; 6 - upper third of $L 2$ body; 7 - middle third of L2 body; 8 - lower third of L2 body; 9 -lower than L2 body

On the contrary, other symptoms, although included in the study from the start, were observed too rarely to be used in the actual analysis and were therefore rejected as not being specific enough for this clinical picture: loss of consciousness in 23 cases (6\%), dysphonia in 20 (5\%), hypersomnia in $20(5 \%)$, abdominal pain in $24(6 \%)$, dysesthesias in $28(8 \%)$, tremor in $29(8 \%)$ and atrophy of various body segments in $22(6 \%)$. It is furthermore notable that only 14 of our patients (4\%) reported sleep apnea.

Concerning the type of clinical course, it was progressive in the majority of cases (239 patients, 64\%), followed by a chronic type (177 patients, representing $31 \%$ ); the remaining were much less frequent (Fig. 10).

\section{Imaging features}

The Descent of the Cerebellar Tonsils (Arnold-Chiari Syndrome Type I) was present is 273 cases (73\%), while other 73 cases (20\%) were interpreted as Impaction of the Cerebellar Tonsils. We have found all degrees of descent in quite balanced proportions; the most frequent variant was the one with the tonsils reaching just in front of the posterior arch of the atlas (Grade 4 in Fig. 2) (75 cases, 20\%) (Fig. 11).

Intramedullary Cysts (Idiopathic Syringomyelia) were detected in 194 cases (52\%), while 139 cases (37\%) were interpreted as Spinal Cord Ischemia-Edema and another 8 cases $(2 \%)$ had only a central canal dilatation. The most frequent location was cervicothoracic with 99 cases $(26 \%)$ and it is worth noting that a cervical syringomyelia with or without variable extension in other vertebral segments was present in 135 cases (36\%). As to the longitudinal extension of the syringomyelic cavity, most frequently it was over 10 vertebral segments (66 cases, 18\%) (Fig. 12).

The Deviation of the Vertebral Column (Idiopathic Scoliosis) was observed in 284 cases (76\%), being mild (up to $\left.10^{\circ} \mathrm{Cobb}\right)$ in the majority (170 cases, 46\%) (Fig. 13).

The position of the tip of the conus medullaris compared to the vertebral levels was very variable; the most frequent one was at the height of the L1L2 disc, found in 87 cases (23\%) (Fig. 14).

As of Occipitocervical Junction Malformations, in this series we found 18 cases (5\%) of Retroflexed Odontoid (RO), 15 cases (4\%) of Basilar Impression (BI), 10 cases (3\%) of Platybasia (PTB) and 6 cases (2\%) of Brainstem Kinking (BSK).

Finally, a total of 267 cases (72\%) were labeled as Multiple-level Disc Disease.

Part II - bivariate analysis

The following statistically significant associations $(p<$ 0.05) have been found:

\section{A. CLINICAL SIGNS ASSOCIATED WITH CRANIAL OR GENERAL SYMPTOMS:}

Deviation of the uvula and/or tongue with: Headache $(p=0.011)$ and Nausea and/or vomiting $(p=$ 0.014);

Spontaneous nystagmus with: Balance alterations $(p=0.020$ Kendall), Tinnitus $(p=0.000)$ and Cognitive deterioration $(\mathrm{p}=0.011$ Kendall);

Positive Romberg test with: Balance alterations $(p=0.002)$;

Decreased grip strength with: Cognitive deterioration $(p=0.021$ Kendall);

Altered sensibility to temperature with: Mood alterations $(p=0.000)$.

\section{B. CLINICAL SIGNS ASSOCIATED WITH MEDULLARY SYMPTOMS:}




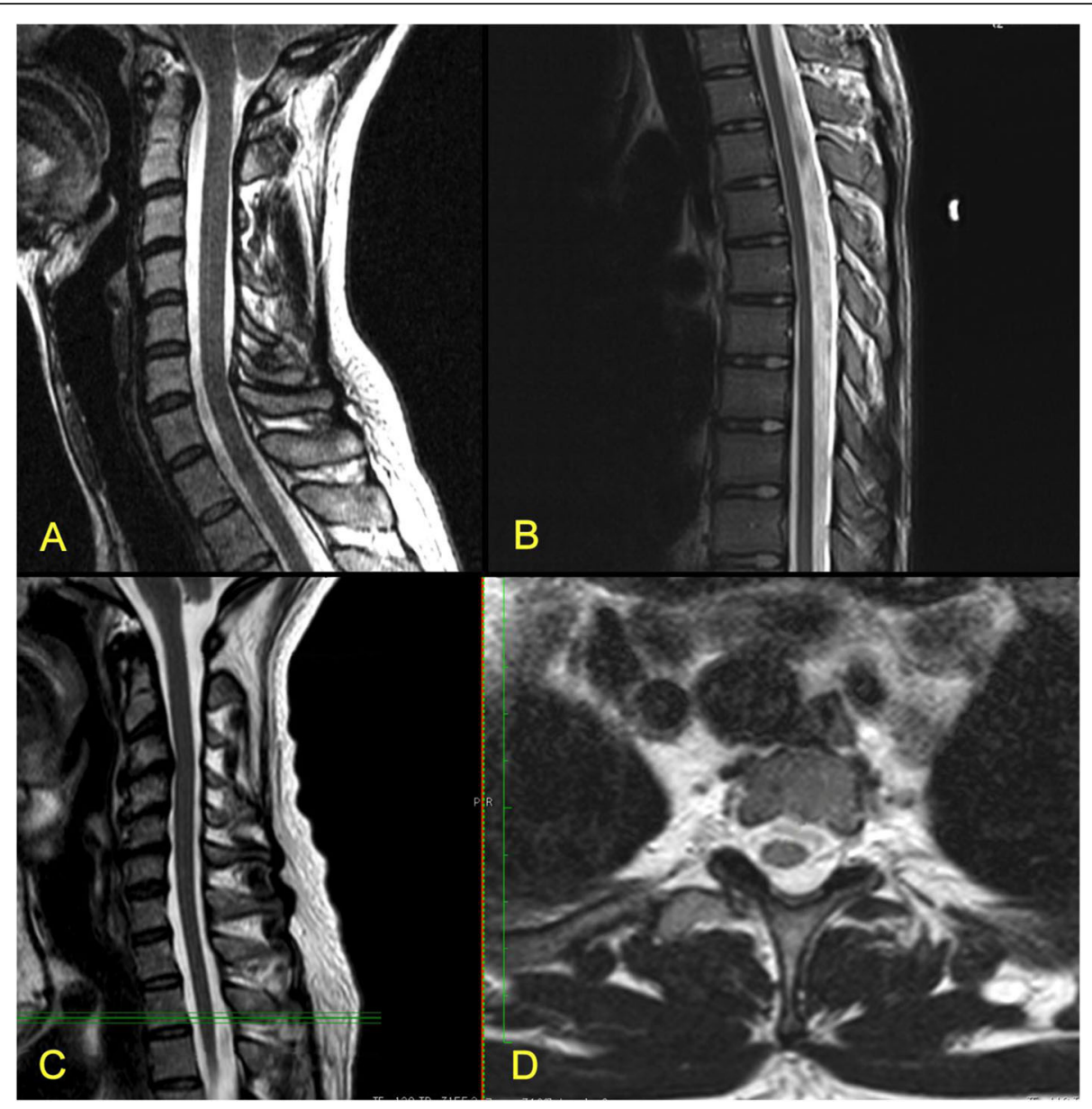

Fig. $8 \mathrm{MRI}$ cuts showing features of Tense Spinal Cord (A, C - cervical spine; B - thoracic spine) and Lateralized Spinal Cord (D, at the level marked with green lines in C)

Altered sensibility to temperature with: Cervical pain $(p=0.004)$, Upper extremity pain $(p=0.000)$, Upper extremity numbness $(p=0.000)$, Upper extremity weakness $(p=0.000)$, Lower extremity pain ( $p=0.045$ Kendall) and Alterations of temperature perception $(p=0.000)$;
Altered sensibility to touch with: Cervical pain $(p=0.044$ Kendall), Upper extremity pain $(p=0.000)$, Upper extremity numbness $(\mathrm{p}=0.000)$, Upper extremity weakness $(p=0.001)$ and Lower extremity pain $(p=0.011)$;

Table 2 Creation of new continuous scale variables - for each given patient, the value of the variable was the sum of the individual values of the different categorical variables, selected according to topographical criteria

\begin{tabular}{lll}
\hline $\begin{array}{l}\text { New continuous } \\
\text { variable }\end{array}$ & Components & $\begin{array}{c}\text { Range of } \\
\text { values }\end{array}$ \\
\hline $\begin{array}{l}\text { General Symptoms } \\
\text { Cranial Symptoms }\end{array}$ & Cognitive deterioration+ Mood alterations + Insomnia + Fatigue & $4-11$ \\
Cervical Symptoms & Cervical pain + Upper limb pain + Upper limb numbness + Upper limb motor loss & $7-15$ \\
$\begin{array}{l}\text { Spinal Cord } \\
\text { Symptoms }\end{array}$ & $\begin{array}{l}\text { Thoracic back pain + Low back pain + Lower limb pain + Thoracic pain + Lower limb numbness + Lower limb } \\
\text { motor loss + Paresthesias + Alterations of temperature perception + Muscular cramps + Sphincter alterations + }\end{array}$ & $11-21$ \\
Cranial Signs & Abnormal gait & Nystagmus + Deviation of the uvula and/or tongue \\
Medullary Signs & Alterations of temperature sensibility + Alterations of sensibility to touch + Upper limb deep tendon reflexes + & 10-25 \\
& Lower limb deep tendon reflexes + Abdominal reflexes + Plantar reflexes + Lasègue's test + Mingazzini's test+ & \\
\hline
\end{tabular}




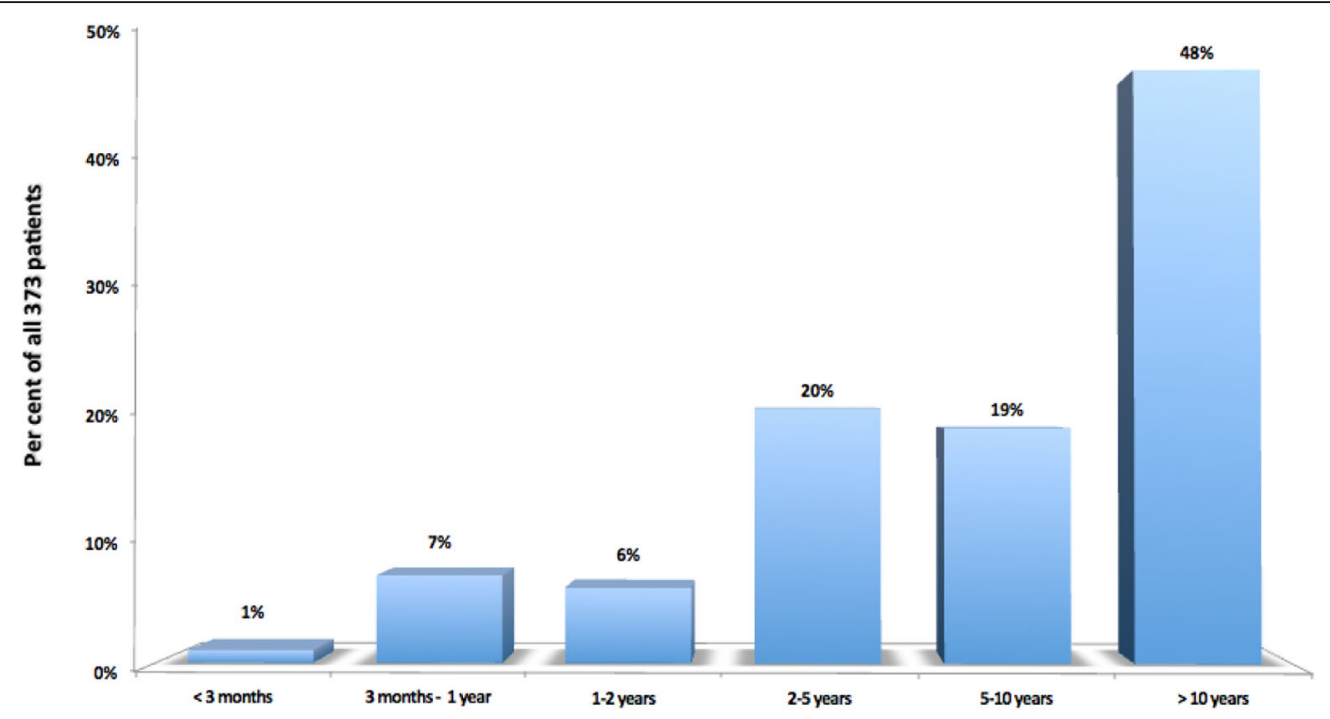

Fig. 9 Time interval from initiation of first symptoms until the diagnostic visit at ICSEB, in the selected 373 patients

Alterations of deep tendon reflexes in upper extremities with: Upper extremity weakness $(p=0.042)$ and Sphincter alterations $(p=0.024$ Kendall);

Decreased grip strength with: Upper extremity weakness $(p=0.000)$;

Alterations of deep tendon reflexes in lower extremities with: Lower extremity weakness $(p=0.002)$ and Gait alteration ( $p=0.046$ Kendall); Positive Mingazzini's test with: Lower extremity weakness $(p=0.001)$.

\section{RELATIONSHIPS BETWEEN CLINICAL VARIABLES (SYMPTOMS AND SIGNS) AND IMAGING FEATURES:}

- Clinical variables associated with Descent of cerebellar tonsils: Headache $(p=0.018)$, Deviation of the uvula and/or tongue $(p=0.013)$ and Decrease of grip strength $(p=0.042)$.

- Clinical variables associated with Intramedullary cyst: Nauseas and/or vomiting $(p=0.000)$, Visual alterations $(p=0.001)$, Tinnitus $(p=0.007)$, Cognitive deterioration $(p=0.001)$, Insomnia $(p=0.021)$, Fatigue $(p=0.000)$, Upper extremity numbness $(p=0.014)$, Alterations of temperature perception $(p=0.019)$, Upper extremity weakness $(p=0.006)$, Deviation of the uvula and/or tongue $(p=0.027)$, Altered sensibility to temperature $(p=0.001)$ and Altered cutaneous abdominal reflexes $(p=0.002)$. If we take into consideration only syringomyelias with cervical component, all of these variables continue to be associated, with the exception of insomnia, and there are also significant associations with: Upper extremity pain $(p=0.003)$, Lower extremity numbness $(p=0.045)$, Altered sensibility to touch $(\mathrm{p}=0.000)$ and Altered cutaneous plantar reflexes $(p=0.010)$.

- Clinical variables associated with Deviation of the vertebral column (Idiopathic scoliosis): Thoracic back pain $(p=0.034)$, Spontaneous nystagmus ( $p=0.038$ Kendall), Altered sensibility to touch $(p=0.013)$, Altered cutaneous abdominal reflexes ( $p=0.044$ Kendall) and Altered cutaneous plantar reflexes $(p=0.001)$.

\section{RELATIONSHIPS AMONG VARIOUS IMAGING FEATURES:}

- Descent of cerebellar tonsils with: Occipitocervical junction malformations ( $p=0.015$ Kendall), Syringomyelia with cervical component $(\mathrm{p}=0.003)$, Level of conus medullaris $(p=0.008)$ and Deviation of the vertebral column ( $p=0.014$ Kendall);

- Level of conus medullaris with Deviation of the vertebral column ( $p=0.045$ Kendall).

Moreover, through Mantel-Haenszel stratified analysis, it results that the positive relationship between the Descent of cerebellar tonsils and the Low-lying conus medullaris only exists in cases with moderate and severe scoliosis. It is also interesting that although seemingly there is no relationship between Descent of cerebellar tonsils and Intramedullary cyst when the latter includes 
Table 3 Frequency of clinical symptoms in the selected 373 patients. ${ }^{1}$ Instability, dizziness, vertigo, etc. ${ }^{2}$ Blurred vision, phosphenes, scotomata, etc. ${ }^{3}$ Sensation of cold hands and/or feet, intolerance/unawareness of coldness/warmth.

${ }^{4}$ Incontinence/retention, urgency, frequency, etc. A Later during the analysis, grouped together as "Cognitive deterioration".

B Later during the analysis, grouped together as "Mood alterations"

\begin{tabular}{|c|c|c|c|}
\hline \multicolumn{2}{|c|}{ Symptom } & \multirow{2}{*}{$\begin{array}{l}\text { Frequency } \\
312\end{array}$} & \multirow{2}{*}{$\begin{array}{l}\text { Percentage } \\
84\end{array}$} \\
\hline 1. & Headache & & \\
\hline 2. & Nausea and/or vomiting & 182 & 49 \\
\hline 3. & Balance alterations $^{1}$ & 268 & 72 \\
\hline 4. & Difficulty swallowing & 141 & 38 \\
\hline 5. & Visual alterations $^{2}$ & 212 & 57 \\
\hline 6. & Double vision & 58 & 16 \\
\hline 7. & Tinnitus & 171 & 46 \\
\hline 8. & Speech disorders ${ }^{\mathrm{A}}$ & 92 & 25 \\
\hline 9. & Memory deterioration ${ }^{A}$ & 162 & 43 \\
\hline 10. & Attention alteration ${ }^{\mathrm{A}}$ & 143 & 38 \\
\hline 11. & Sadness ${ }^{B}$ & 100 & 27 \\
\hline 12. & Anxiety $^{B}$ & 45 & 12 \\
\hline 13. & Nervousness ${ }^{\mathrm{B}}$ & 196 & 53 \\
\hline 14. & Sleeplessness & 181 & 49 \\
\hline 15. & Fatigue & 183 & 49 \\
\hline 16. & Upper extremity pain & 167 & 45 \\
\hline 17. & Lower extremity pain & 208 & 56 \\
\hline 18. & Thoracic pain & 81 & 22 \\
\hline 19. & Cervical pain & 268 & 72 \\
\hline 20. & Thoracic back pain & 243 & 65 \\
\hline 21. & Lumbosacral pain & 270 & 72 \\
\hline 22. & Upper extremity numbness & 110 & 30 \\
\hline 23. & Lower extremity numbness & 76 & 20 \\
\hline 24. & Paresthesias & 262 & 70 \\
\hline 25. & Alterations of temperature perception ${ }^{3}$ & 146 & 39 \\
\hline 26. & Cramps & 44 & 12 \\
\hline 27. & Upper extremity weakness & 182 & 49 \\
\hline 28. & Lower extremity weakness & 175 & 47 \\
\hline 29. & Sphincter alterations ${ }^{4}$ & 192 & 52 \\
\hline 30. & Gait alteration & 170 & 46 \\
\hline
\end{tabular}

all locations, in fact there is one when analyzed in detail, but the positive association between Descent of cerebellar tonsils and Syringomyelia with a cervical component is counterbalanced by a negative association of Descent of cerebellar tonsils with Syringomyelia with thoracic and/or lumbar locations.

The comparison of means and the $t$-test for independent samples, applied to the new continuous variables, formed by grouping symptoms and signs according to topographic criteria (Table 2) reveals the following positive relationships: Cervical symptoms - Syringomyelia with cervical component; Cranial symptoms - Descent of cerebellar tonsils; Cranial signs - Descent of cerebellar tonsils; and Medullary signs - Occipitocervical junction malformations.

It is worth mentioning that in all syringomyelias (intramedullary cysts), as well as if one considers only those with cervical component, there are less general and cranial symptoms than in patients without intramedullary cysts (they are negatively associated).

Concerning the Pearson correlation coefficient applied to the same new continuous variables, we observed good correlations within the group of clinical symptoms and signs - the strongest ones being between General symptoms - Cranial symptoms $(\mathrm{r}=0.531, p=0.000)$, Medullary symptoms - Medullary signs $(\mathrm{r}=0.523, \mathrm{p}=0.000)$, Cervical symptoms - Medullary symptoms $(r=0.513$, $\mathrm{p}=0.000)$, Cranial symptoms - Medullary symptoms $(\mathrm{r}=0.420, \mathrm{p}=0.000)$ and General symptoms - Medullary symptoms $(\mathrm{r}=0.414, \mathrm{p}=0.000)$. There are statistically significant positive correlations $(p<0.05)$, nevertheless weaker ( $r$ between 0.106-0.149), between Cranial symptoms - Descent of cerebellar tonsils, Cranial signs - Descent of cerebellar tonsils, Cervical symptoms Intramedullary cysts and Medullary symptoms - Intramedullary cysts. Similarly, there are weak statistically significant negative correlations ( $\mathrm{p}<0.05$, $\mathrm{r}$ between 0.120 0.197 ) between General symptoms - Deviation of the vertebral column, General symptoms - Intramedullary cysts, Cranial symptoms -Intramedullary cysts, Medullary symptoms - Descent of cerebellar tonsils and Cranial signs - Intramedullary cysts. Generally, it is noteworthy that Descent of cerebellar tonsils has positive correlations with cranial symptoms and signs, while the second main image abnormality, Intramedullary cysts, has positive correlations with cervical symptoms and medullary signs.

\section{Discussion}

Historically, the mentioned pathologies have been defined in general with one or two publications, like Fuchs in 1910 [3] and Lichtenstein in 1940 [4] for the tethered cord syndrome; Hoffman in 1976 [7] for occult tethered cord and Garceau in 1953 [5], for the cord-traction syndrome and filum terminale syndrome. In none of the above was any correlation demonstrated between Idiopathic Syringomyelia, Arnold-Chiari Syndrome Type I, Idiopathic Scoliosis, Platybasia, Basilar Impression, Retroflexed Odontoid, Brainstem Kinking and a disharmonic growth conflict between the neural axis and spine, with the retention of an apparently normal filum terminale on imaging. 
Table 4 Frequency of clinical signs in the selected 373 patients

\begin{tabular}{|c|c|c|c|}
\hline Signs & & Frequency & Percentage \\
\hline 1. & Spontaneous nystagmus & 204 & 55 \\
\hline 2. & Deviation of uvula and/or tongue & 237 & 64 \\
\hline 3. & Altered sensibility to temperature & 257 & 69 \\
\hline 4. & Altered sensibility to touch & 242 & 65 \\
\hline 5. & Altered deep tendon reflexes in upper extremities & 322 & 86 \\
\hline 6. & Altered deep tendon reflexes in lower extremities & 309 & 83 \\
\hline 7. & Altered cutaneous abdominal reflexes & 254 & 68 \\
\hline 8. & Altered cutaneous plantar reflexes ${ }^{1}$ & 274 & 73 \\
\hline 9. & Positive straight leg-raising test & 165 & 44 \\
\hline 10. & Positive Mingazzini's test & 245 & 66 \\
\hline 11. & Positive Romberg's test & 188 & 50 \\
\hline 12. & Decreased grip strength & 259 & 70 \\
\hline
\end{tabular}

${ }^{1}$ Babinski's sign was present on one or both sides in 109 patients (29\%)

None of these diseases has ever been related with this pathogenic mechanism, with the exception of the doctoral thesis "Contribution to the etiology of idiopathic syringomyelia" [26] in 1992, where, given the statistical evidence of a low position of the conus medullaris in Idiopathic Syringomyelia patients, has been postulated the existence of an axial caudal force affecting all of the human nervous system.

In our publications of 1996 [27, 28], the apparently normal Filum terminale, i.e. not showing any abnormality on imaging, is considered the transmitter or causative agent of the traction of the spinal cord and entire central nervous system, affecting them both and their bony surroundings - skull and spine, thus being the common cause of Arnold-Chiari Syndrome Type I, Idiopathic Syringomyelia, Idiopathic Scoliosis, Platybasia, Basilar Impression, Retroflexed Odontoid and Brainstem Kinking. We call "Neuro-Cranio-Vertebral Syndrome" the presence of one or more of these diseases in a patient, and when it is impossible to identify a traumatic, tumoral, infectious, obvious malformative congenital or any other cause, we call it "Filum Disease".

Roth, in 1981 and 1986 [19, 20], proposed the disharmonic growth between the spine and the spinal cord to explain scoliosis and the Arnold-Chiari Syndrome I without any neurovertebral malformation. We regard

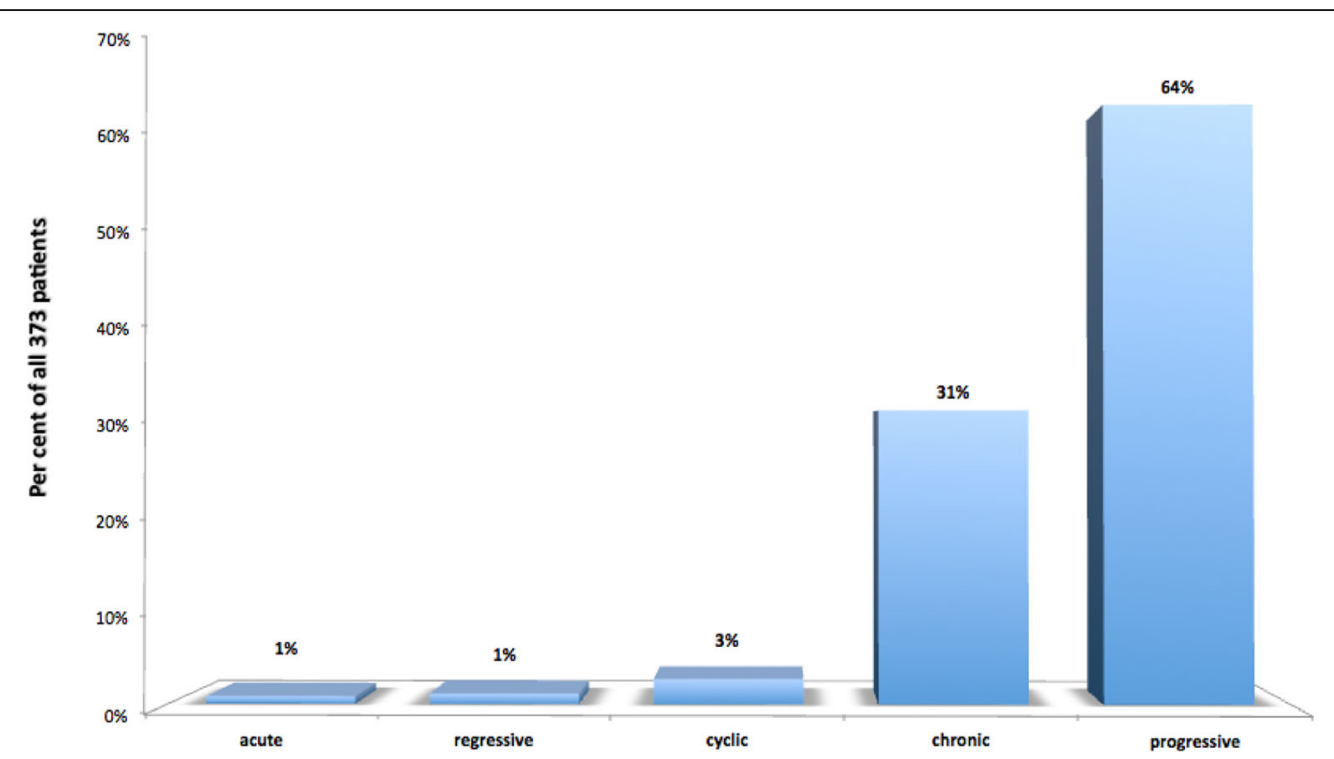

Fig. 10 Type of clinical course in the selected 373 patients. Acute = symptoms appearing in the preceding 6 months; regressive =symptoms slowly diminishing or disappearing over time; cyclic = symptoms presenting in flare-ups separated by periods of normality; chronic=symptoms more or less constant over long periods of time; progressive= symptoms increasing in intensity and/or number over time 


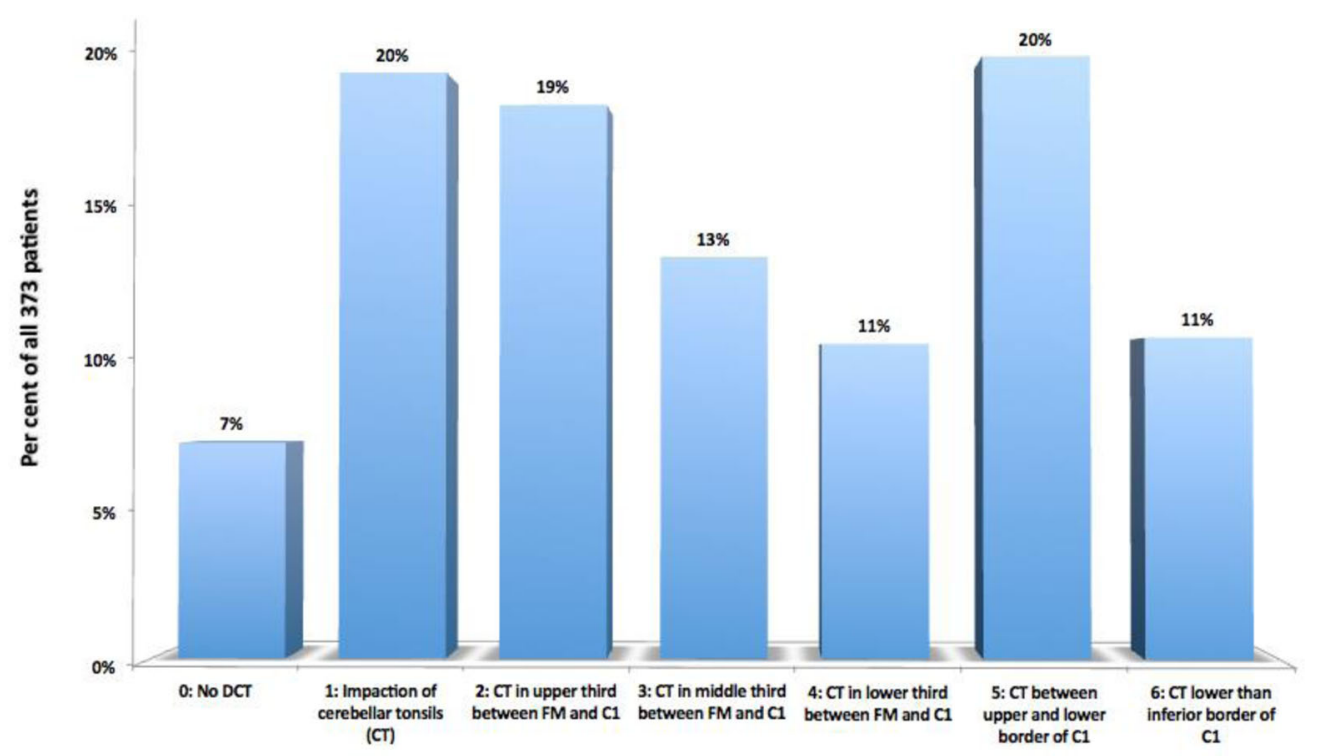

Fig. 11 Descent of the cerebellar tonsils (DCT) in relation to FM, posterior arch of $C 1$ and $C 2$, in the selected 373 patients. CT= cerebellar tonsils; $\mathrm{FM}=$ foramen magnum; $\mathrm{C} 1$ = first cervical vertebra

this disharmonic growth, together with the mechanical conflict exerted by the seemingly normal Filum terminale, as causative of various idiopathic anomalies, such as Idiopathic Syringomyelia, Idiopathic Scoliosis, Basilar Impression, Retroflexed Odontoid, Platybasia and Brainstem Kinking.

Caudal traction is presumed to be present in all human beings from the ninth week of intrauterine life and any idiopathic Deviation of the Vertebral Column can be an expression of this same caudal traction force. Testut and Latarjet Péré's quote from 1900 [30] is noteworthy: "In 100 adults, examined regarding this topic [referring to the lateral inflexions of the spine], he confirmed their existence 93 times and the spine was straight only 7 times. The existence of lateral curvatures can therefore be considered normal." This indicates a potential prevalence of $93 \%$ of a coronal plane DVC not always perceived and therewith the possible existence of the axial caudal force and hence the Filum Disease. As Deviation of the Vertebral Column is one of the multiple ways through which

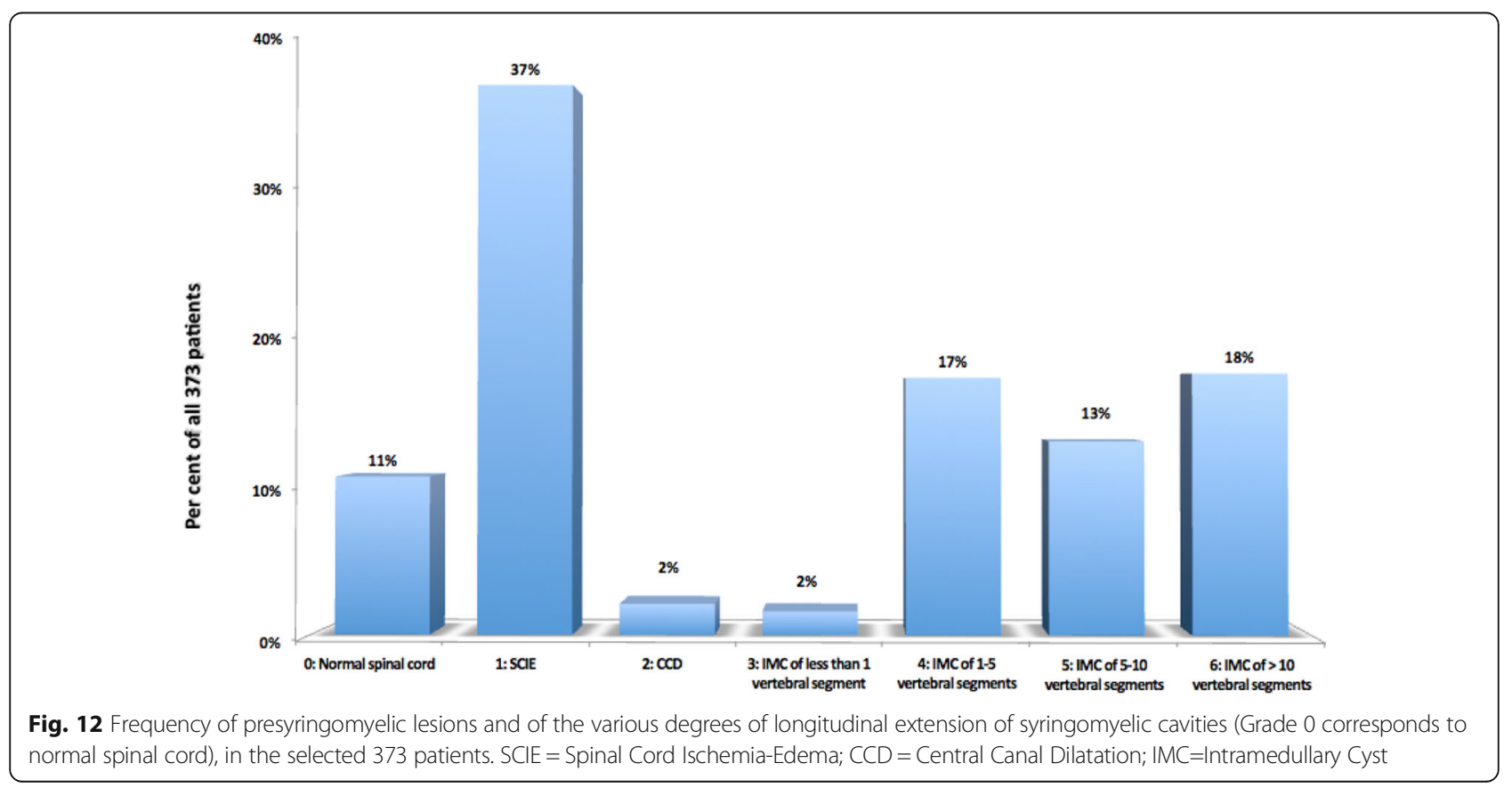




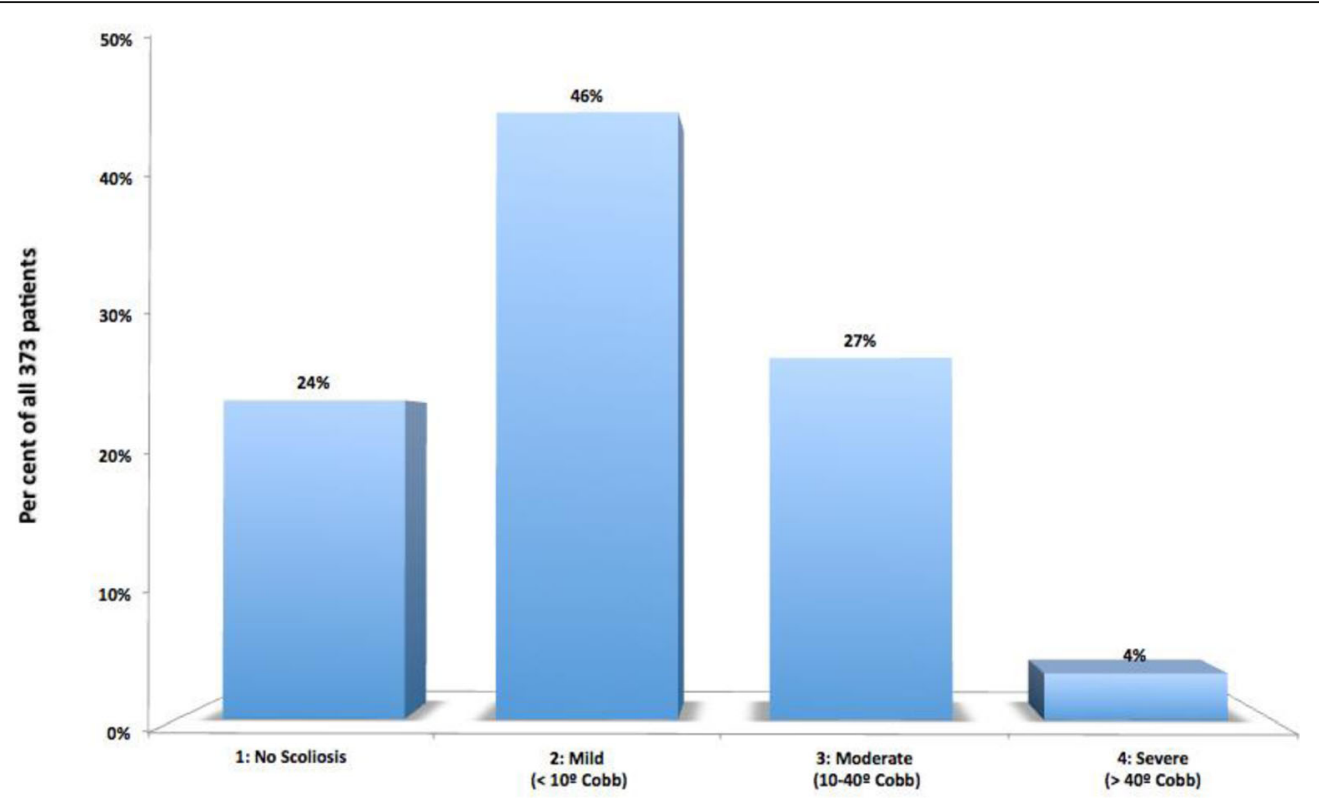

Fig. 13 Presence of DVC (IS), classified by its severity measured according to Cobb's method, in the selected 373 patients

Filum Disease can manifest itself, it would not be too adventurous to believe that there are signs on imaging and symptoms and signs in the clinical picture, in the majority of humans, usually unnoticed, that could confirm the possible universal existence of a mechanical conflict between the neuroaxis and the spine.

We are aware that patient selection depends on a previous diagnosis of certain conditions, initiated by health care professionals independent of our center, as well as on the patients' assimilation of these diagnoses and of their proposed surgical solution or lack of therapeutic proposal. Although several factors can interfere in producing a selection bias (intensity of the clinical picture, individual temperamental and character features, regional cultural habits, ease of Internet use, social status, etc.) we can assume that even this search for a second

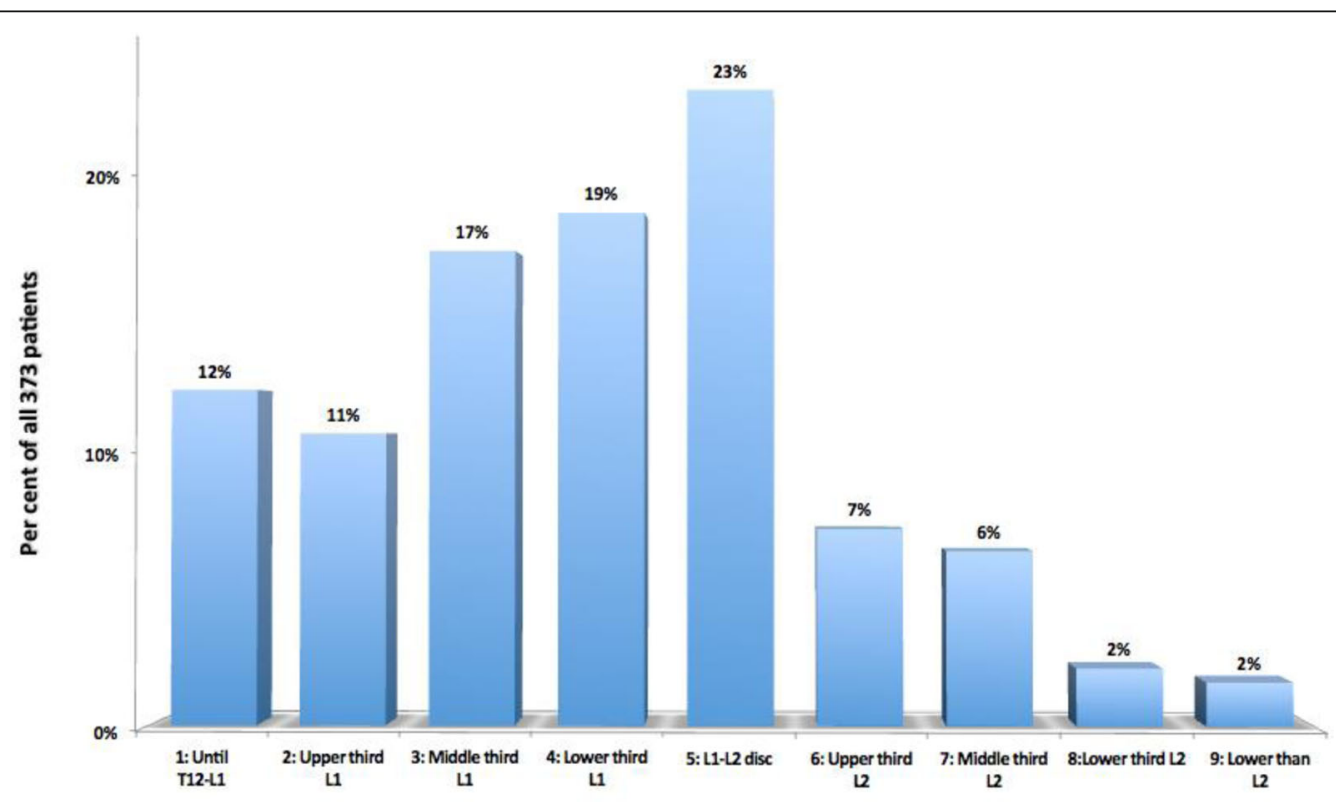

Fig. 14 Height of the tip of the conus medullaris according to the corresponding vertebral levels (D12, L1, L2), from cranial to caudal, in the selected 373 patients 
opinion, as well as their understanding of the obvious limits of the current treatment, define the patients affected by this condition and therefore should not discourage any researcher trying to explain this clinical and imaging picture. Our patient sample's representability for all population suffering with these conditions is not worrisome if one considers that it is merely the first description of a new pathology, awaiting future studies in which this global population should be better characterized in more objective conditions.

\section{Based on the results in 373 cases Epidemiology}

There is a predominance of the female gender (72\%), the most frequent age to be diagnosed is 33 years (average 33.66 years, with standard deviation 15.87 years) and the time interval lapsed from onset until diagnosis is most often longer than 10 years, in $48 \%$ of cases.

\section{Symptoms}

The following principal symptoms define the clinical picture of FD in decreasing order of frequency: headache $84 \%$, lumbosacral pain $72 \%$, cervical pain $72 \%$, balance alteration $72 \%$, paresthesias $70 \%$, thoracic back pain $65 \%$, visual alterations $57 \%$, lower extremity pain $56 \%$, nervousness $53 \%$, sphincter alterations $52 \%$, fatigue $49 \%$, upper extremity weakness $49 \%$, nausea and/or vomiting $49 \%$.

\section{Signs}

The most frequent signs in Filum Disease, in decreasing order of frequency, are: altered deep tendon reflexes in upper extremities $86 \%$, altered deep tendon reflexes in lower extremities $82 \%$, altered plantar reflexes $73 \%$, decreased grip strength $70 \%$, altered sensibility to temperature $69 \%$, altered abdominal reflexes $68 \%$, positive Mingazzini's test $66 \%$, altered sensibility to touch $65 \%$, deviation of the uvula and/or tongue $64 \%$, spontaneous nystagmus $55 \%$, positive Romberg's test $50 \%$, positive straight leg-raising test $44 \%$.

Significantly, the statistical analysis confirms the presence of correlations between Conus Medullaris level and Descent of cerebellar tonsils $(p=0.008)$ and between Conus Medullaris level and Deviation of the vertebral column $(p=0.045)$. It also confirms the existence of a correlation between Descent of cerebellar tonsils and Syringomyelia with cervical component $(p=0.003)$, coexisting with an interestingly inverse - that is, negative - association between Descent of cerebellar and "low" Syringomyelia (without cervical component, i.e. thoracic or thoracolumbar) $(p=0.001)$. We also detected a positive correlation between Descent of cerebellar tonsils and Deviation of the vertebral column $(p=0.014)$.

Out of all symptoms and clinical signs, only the unilaterally or bilaterally positive straight leg-raising test ( $p=$
0.048) and the unilaterally or bilaterally decreased grip strength (Kendall $p=0.019$ ) have correlations with the level of conus medullaris. Altered deep tendon reflexes have correlations with Syringomyelia with cervical component $(p=0.005)$ and with Deviation of the vertebral column $(p=0.000)$.

\section{Imaging}

Relevant imaging features in decreasing order of frequency are: altered position of cerebellar tonsils 93\% (Descent of cerebellar tonsils 73\% and impaction Cerebellar Tonsils 20\%); Low Conus Medullaris below T12-L1 88\%; Deviation of the vertebral column in $76 \%$; multiple disc disease $72 \%$; syringomyelic cavity $52 \%$.

\section{Conclusion}

These observations are compatible with the conclusions of the thesis: the caudal traction force applied to the nervous system by means of the filum terminale is expressed in the form of Descent of cerebellar tonsils as the entire encephalon, including its lowermost part, the cerebellar tonsils, shift through the foramen magnum; the spine, seeking to minimize trauma on the spinal cord, bends and creates abnormal spinal curvatures such as scoliosis, kyphosis, hyperlordosis, rotoscoliosis, straightening; the central spinal cord tissue suffers ischemia and necrosis with production of a cavity filled with interstitial fluid or serum, the syringomyelic cavity; by acting on the skull and brainstem at the beginning of bone maturation, Platybasia, Basilar Impression, Retroflexed Odontoid and Brainstem Kinking develop. The course of the syringomyelic cavity is toward fistulization and mixing of the intracavitary fluid with cerebrospinal fluid, towards redilatation when there is a valvular mechanism or toward collapse and spinal cord atrophy.

Concluding a doctoral thesis and resulting published papers $[26-28,31,32]$, we have proceeded thus to the description of a new nosological and etiopathogenic concept, proposing the pathological conditions of Filum Disease, when its origin is congenital, and Neuro-Cranio-Vertebral Syndrome, when the nature of the mechanical conflict between neuraxis and spine is acquired.

It is important for future studies to help understand better the origin of the axial caudal force, in order to assess the impact of the Filum Disease in the individual and in the population in general, which will help to comprehend the magnitude, consequences and anomalies of the asynchronic growth between neuraxis and spine on the central nervous system, skull and spine, as well as the rest of the organism. This knowledge would allow a new line of surgical and genetic treatments of these diseases. In the field of biology, it may be of interest to determine the presence of Filum Disease in other 
species belonging to the mammalia class, and also its absence in non-mammalian vertebrates.

The most relevant practical corollary of this paradigm shift is the solution that we propose in order to correct or prevent these abnormalities as soon as possible, consisting of the surgical intervention of Filum terminale sectioning. This is a minimally invasive procedure aimed at the release of this fibrous structure right above its coccygeal insertion, as it has been performed in most of the patients included in this report, as an alternative to many higher-risk and challenging surgical techniques tailored to solve these conditions [31, 32]. Of course, as they stand well out of the diagnostic and nosological purpose of this paper, these therapeutic innovations will be the subject of a future publication.

\section{Abbreviations \\ ACSI: Arnold-Chiari Syndrome Type I; BI: Basilar Impression; BSK: Brainstem Kinking; CCD: Central Canal Dilatation; DCT: Descent of Cerebellar Tonsils; DVC: Deviation of the Vertebral Column; FD: Filum Disease; FM: Foramen magnum; FS : Filum System ${ }^{\oplus}$; IMC: Intramedullary Cyst; IS: Idiopathic Scoliosis; ISM: Idiopathic Syringomyelia; MRI: Magnetic resonance imaging; NCVS: Neuro-cranio-vertebral syndrome; LCM: Low-lying conus medullaris; PTB: Platybasia; R\&D: Research \& Development; RO: Retroflexed Odontoid; SCIE: Spinal Cord Ischemia-Edema}

\section{Acknowledgements}

Miguel Bautista Royo-Salvador thanks Prof. Dr. Jose Maria Domenech Mateu $(+)$, Professor of Anatomy and Human Embryology of the Autonomous University of Barcelona and his successor of the professorship, Prof. Dr. Alfonso Rodriguez Baeza, for their scientific support and also Dr. José Solé Llenas (†) for his support in the realization of the doctoral thesis - Contribution to the etiology of syringomyelia - and the subsequent description of the Filum Disease in two publications in 1996.

Mr. Juan Manuel Jené Gaspar updated the FileMaker Pro database and assisted in image pre-processing and editing of the manuscript. Ms. Katharina Kühn assisted in the translation and review of the manuscript. Ms. Gioia Luè contributed to the management of the institute's $R+D+i$ accreditation by the Spanish Accreditation and Innovation Agency, to the research on the Filum Disease and the processes and presentations together with MBRS of conferences about patients affected by the FD, as well as the organization of patient and physician meetings in Italy, France and Spain, where the concepts of FD and NCVS were presented publicly for the first time. Ms. Mara Espino Hernández contributed administrative, social and financial management to the projects at Institut Chiari \& Siringomielia \& Escoliosis de BarceIona, Chiari \& Scoliosis \& Syringomyelia Foundation, Filum Academy Barcelona. We thank all the other staff at the Institut Chiari \& Siringomielia \& Escoliosis de Barcelona that has contributed to patient care and data collection, preparation and analysis. We thank all our patients and caregivers, without whom this work would not have been possible.

\section{Authors' contributions}

Study Design: MRS.

Data Collection: MFR, HS, MRS.

Statistical Analysis: $\mathrm{HS}, \mathrm{GBO}$.

Data interpretation: MRS, HS

Manuscript Preparation: MRS, HS.

Literature Search: MRS, HS.

All authors have read and approved he manuscript.

\section{Funding}

No funding was received for this research.

\section{Availability of data and materials}

The datasets used and/or analysed during the current study are available from the corresponding author on reasonable request.

\section{Ethics approval and consent to participate}

For this article we used our center's database of patient records retrospectively; patient data were anonymized in accordance with the legislation existing at the moment when the study was initiated (2009), without considering as required the opinion of an ethics committee, because the necessary technical and organizational guarantees and measures were adopted as established in EU data protection directive 2016/679 (article 89.1). As mentioned above, the Institut Chiari \& Siringomielia \& Escoliosis de Barcelona holds Research \& Development (R\&D) certification 1583.001.16-160920-CER-RD.001 from the Spanish Innovation Certification Agency (ACIE) and ENAC certification 33/CPRO74, Certificate IQNet and AENOR Quality Management System ISO 9001:2015, Registration Number: ES-0081/2015 for the following fields of activities: Research, Diagnosis and Treatment of the Filum Disease and Quality Management Certification according to UNE-EN ISO 9001:2008 standards.

\section{Consent for publication}

For this type of study formal consent for the publication of participant data and imaging is not required given that only anonymized (non-identifiable) imaging has been used; according to organic law 3/2018 of personal data protection (additional provision 17.d) this is compliant provided that a confidentiality commitment has been made and specific safety measures have been adopted.

\section{Competing interests}

Conflict of Interest: All authors certify that they have no affiliations with or involvement in any organization or entity with any financial interest (such as honoraria; educational grants; participation in speakers' bureaus; membership, employment, consultancies, stock ownership, or other equity interest; and expert testimony or patent-licensing arrangements), or non-financial interest (such as personal or professional relationships, affiliations, knowledge or beliefs) in the subject matter or materials discussed in this manuscript.

\section{Author details}

'Institut Chiari \& Siringomielia \& Escoliosis de Barcelona, Passeig Manuel Girona 16, 08034 Barcelona, Spain. ${ }^{2}$ Anesthesia Department, CIMA Hospital, Barcelona, Spain.

Received: 12 September 2019 Accepted: 22 April 2020

Published online: 11 May 2020

\section{References}

1. Johnson A. Sacrum of a child containing a fatty tumour connected with the anterior of the spinal canal. Lancet. 1857;2:35-6.

2. Jones W. Spina bifida occulta: no paralytic symptoms until seventeen years of age: spine trephined to relieve pressure on the cauda equina: recovery. Br Med J. 1891;1:173-4.

3. Fuchs A. Ueber Beziehungen der Enuresis nocturna zu Rudimentärformen der Spina bifida occulta (Myelodysplasie). Wien Med Wochenschr. 1910;80: 1569-73.

4. Lichtenstein BW. Spinal dysraphism. Spina Bifida and myelodysplasia Archives of Neurology \& Psychiatry. 1940;44:792-809.

5. Garceau GJ. The filum terminale syndrome (the cord-traction syndrome). J Bone Joint Surg. 1953;35:711-6.

6. Jones PH, Love JG. Tight filum terminale. Arch Surg. 1956;73:556-66.

7. Hoffman HJ, Hendrick EB, Humphreys RP. The tethered spinal cord: its protean manifestations, diagnosis and surgical correction. Childs Brain. 1976; 2:145-55.

8. Yamada S, Zinke DE, Sanders D. Pathophysiology of "tethered cord syndrome". J Neurosurg. 1981;54:494-503.

9. Bademci G. Prevalence of primary tethered cord syndrome associated with occult spinal Dysraphism in primary school children in Turkey. Pediatr Neurosurg. 2006;42:4-13.

10. Sahmat A, et al. The prevalence and distribution of Spina bifida in a single major referral Center in Malaysia. Front Pediatr. 2017;5:237.

11. Aghakhani JN, Parker F, Tadie M. Syringomyelia and Chiari abnormality in the adult. Analysis of the results of a cooperative series of 285 cases. Neurochirurgie. 1999;45(Suppl 1):23-36.

12. Anderson FM. Occult spinal dysraphism. Diagnosis and management The Journal of Pediatrics. 1968;73:163-77. 
13. Avellaneda A, Isla A, Izquierdo M, editors. Malformaciones de la Unión Cráneo-Cervical (Chiari I y Siringomielia). Madrid: Consensus document. Editorial Médica A.W.W.E. S. A; 2009.

14. Klekamp J, Samii M. Syringomyelia: diagnosis and treatment springer. Heidelberg: Berlin; 2012.

15. Marés R. Aportación de la resonancia a estudio de la siringomielia. Correlaciones clínico-morfológicas y precisiones fisiopatológicas. Doctoral thesis: Autonomous University of Barcelona, Barcelona; 1988.

16. Massimi L Della Pepa GM Caldarelli M Di Rocco C (2012) Abrupt clinical onset of Chiari type I/syringomyelia complex: clinical and physiopathological implications. Neurosurg Rev 35:321-329.

17. Ollivier D'Angers CP (1837) Traité des maladies de la moelle épinière; contenant l'histoire anatomique, physiologique et pathologique de ce centre nerveux chez l'homme. Mequignon-Marvis, Paris.

18. Tubbs RS, Oakes WJ, Heimburger RF. The relationship of the spinal cord to scoliosis. J Neurosurg. 2004;101:228-33.

19. Roth M. Idiopathic scoliosis from the point. View of the Neuroradiologist Neuroradiology. 1981;21:133-8.

20. Roth M. Cranio cervical growth collision: another explanation of the ArnoldChiari malformation and of basilar impression. Neuroradiology. 1986;28:187-94.

21. Porter RW. Can a short spinal cord produce scoliosis? Eur Spine J. 2001;10:2-9.

22. Porter RW. The pathogenesis of idiopathic scoliosis: uncoupled neuroosseous growth? Eur Spine J. 2001;10:473-81.

23. Dickson RA, Lawton JO, Archer IA, Butt WP. The pathogenesis of idiopathic scoliosis. Biplanar spinal asymmetry The Journal of Bone \& Joint Surgery (British Volume). 1984;66:8-15.

24. Chu WCW, et al. Relative shortening and functional tethering of spinal cord in adolescent scoliosis - result of an asynchronous neuro-osseous growth, summary of an electronic focus group debate of the IBSE. Scoliosis. 2008;3. https://doi.org/10.1186/1748-7161-3-8.

25. Milhorat TH, et al. Association of Chiari malformation type I and tethered cord syndrome: preliminary results of sectioning filum terminale. Surg Neurol. 2009:72:20-35.

26. Royo-Salvador MB. Aportación a la etiología de la siringomielia. Doctoral thesis: Autonomous University of Barcelona, Barcelona; 1992.

27. Royo-Salvador MB. Syringomyelia, scoliosis and idiopathic Arnold-Chiari malformations: a common etiology. Rev Neurol. 1996;24:937-59.

28. Royo-Salvador MB (1996) [Platybasia, basilar groove, odontoid process and kinking of the brainstem: a common etiology with idiopathic syringomyelia, scoliosis and Chiari malformations] Revista de Neurología 24:1241-1250.

29. Weyreuther M, Heyde CE, Westphal M, Zierski J, Weber U. Inflammatory conditions. In: MRI atlas orthopedics and neurosurgery the spine. Berlin Heidelberg: Springer; 2007. p. 143-94.

30. Testut L. Tratado de Anatomía Humana. Salvat Editores, Barcelona: Volume I; 1926.

31. Royo-Salvador MB, Sole-Llenas J, Domenech JM, Gonzalez-Adrio R. Results of the section of the filum terminale in 20 patients with syringomyelia, scoliosis and Chiari malformation. Acta Neurochir. 2005;14:515-23.

32. Royo-Salvador MB. A new surgical treatment for syringomyelia, scoliosis, Arnold-Chiari malformation, kinking of the brainstem, odontoid recess, idiopathic basilar impression and platybasia. Rev Neurol. 1997;25:523-30.

\section{Publisher's Note}

Springer Nature remains neutral with regard to jurisdictional claims in published maps and institutional affiliations.

\section{Ready to submit your research? Choose BMC and benefit from:}

- fast, convenient online submission

- thorough peer review by experienced researchers in your field

- rapid publication on acceptance

- support for research data, including large and complex data types

- gold Open Access which fosters wider collaboration and increased citations

- maximum visibility for your research: over $100 \mathrm{M}$ website views per year

At $\mathrm{BMC}$, research is always in progress.

Learn more biomedcentral.com/submissions 